\title{
Synthesis of Europium-Doped Fluorapatite Nanorods and Their Biomedical Applications in Drug Delivery
}

\author{
Haifeng Zeng ${ }^{1}$, Xiyu Li ${ }^{2}$, Muyang Sun ${ }^{3}$, Sufan $\mathrm{Wu}^{1, *}$ and Haifeng Chen ${ }^{3, *}$ \\ 1 Department of Plastic Surgery, Zhejiang Provincial People's Hospital, \\ People's Hospital of Hangzhou Medical College, Hangzhou 310014, China; y-zhf@163.com \\ 2 State Key Laboratory of Oral Diseases, West China Hospital of Stomatology, Sichuan University, \\ Chengdu 610041, China; lixiyu@scu.edu.cn \\ 3 Department of Biomedical Engineering, College of Engineering, Peking University, Beijing 100871, China; \\ haifeng.chen@pku.edu.cn \\ * Correspondence: sufanwu@163.com (S.W.); haifeng.chen@pku.edu.cn (H.C.); \\ Tel.: +86-571-85893228 (S.W.); +86-10-62754396 (H.C.)
}

Academic Editor: Svetlana V. Eliseeva

Received: 5 April 2017; Accepted: 4 May 2017; Published: 6 May 2017

\begin{abstract}
Europium (Eu)-doped fluorapatite (FA) nanorods have a biocompatibility similar to that of hydroxyapatite (HA) for use as cell imaging biomaterials due to their luminescent property. Here, we discuss the new application of europium-doped fluorapatite (Eu-FA) nanorods as an anticancer drug carrier. The Eu-FA nanorods were prepared by using a hydrothermal method. The morphology, crystal structure, fluorescence, and composition were investigated. The specific crystal structure enables the effective loading of drug molecules. Doxorubicin (DOX), which was used as a model anticancer drug, effectively loaded onto the surface of the nanorods. The DOX release was $\mathrm{pH}$-dependent and occurred more rapidly at $\mathrm{pH} 5.5$ than at $\mathrm{pH} 7.4$. The intracellular penetration of the DOX-loaded Eu-FA nanorods (Eu-FA/DOX) can be imaged in situ due to the self-fluorescence property. Treatment of melanoma A375 cells with Eu-FA/DOX elicited a more effective apoptosis rate than direct DOX treatment. Overall, Eu-FA exhibits potential for tracking and treating tumors and may be potentially useful as a multifunctional carrier system to effectively load and sustainably deliver drugs.
\end{abstract}

Keywords: lanthanides; fluorapatite; drug loading; nano carrier

\section{Introduction}

Fluorapatite (FA) is one of the inorganic constituents of bone or teeth and is used for hard tissue repairs and replacements [1]. $\mathrm{FA}\left(\mathrm{Ca}_{10}\left(\mathrm{PO}_{4}\right)_{6} \mathrm{~F}_{2}\right)$ can be synthetically prepared from hydroxyapatite and contains a suitable molecular concentration of $\mathrm{OH}$ - groups and $\mathrm{F}^{-}$ions [2]. Nanophase hydroxyapatite or fluorapatite do not have fluorescence characteristics; in order to obtain these properties, the luminescent center should be added. Some scholars tend to integrate HA with fluorescein isothiocyanate (FITC) to label and track HeLa cells [3]. However, FITC demonstrates a short quenching time and poor stability in vivo. When doped with lanthanides $\left(\mathrm{Eu}^{3+} \mathrm{Tb}^{3+}\right.$ or $\left.\mathrm{Gd}^{3+}\right)$, this material exhibits special photoluminescence and has the potential for application in biomedical studies [4-6]. Some lanthanide ion-doped materials $\left(\mathrm{Eu}^{3+}\right.$ or $\left.\mathrm{Tb}^{3+}\right)$ can emit visible fluorescence (i.e., green or red) when excited by ultraviolet or blue excitation wavelengths. In comparison to fluorescent dyes or semiconductor quantum dots (QDs), these lanthanide-doped nanoparticles are advantageous due to their photostability, sharp visible emission bandwidth, and nontoxicity [7-9]. In previous cell labeling and tracking studies, lanthanide ion-doped fluorapatite exhibited long excited state lifetimes and no toxicity to bone marrow mesenchymal stem cells [10,11]. 
Their high surface-to-volume ratio, reactivities, and biocompatibility make FA nanorods favorable for use in drug delivery studies [12,13]. In this study, europium-doped fluorapatite (Eu-FA) nanorods were prepared and characterized. In addition, the obtained multifunctional Eu-FA nanorods were employed as a drug delivery carrier to investigate their drug loading and release properties using doxorubicin (DOX) as a model drug. Melanoma A375 cells were treated with DOX-loaded Eu-FA nanorods (Eu-FA/DOX) to confirm that Eu-FA/DOX induced apoptotic behavior in the tumor cells. The loading capacity of DOX and its release profile were investigated, and the in vitro biological efficacy of the intracellular delivery system was confirmed.

\section{Results and Discussion}

The TEM results indicate that the Eu-FA crystals are on the nanoscale with a rod-like morphology (Figure 1A). The TEM image also indicates that the Eu-FA nanorods are straight with a uniform morphology and good crystallinity. The diameters of the Eu-FA nanorods are 20-40 nm, with lengths ranging from 100 to $170 \mathrm{~nm}$. Figure 1B shows the nanoparticle powders under UV light in an Eppendorf tube and a converted fluorescence microscope. Figure $1 C$ shows the $X$-ray diffraction patterns (XRD) of the synthesized Eu-FA nanorods. All of the diffraction peaks can be indexed to the classical hexagonal phase according to ICDD 15-0876. The sharp characteristic peaks at approximately 25.91 and 31.91 correspond to the (002) and (211) lattice planes. Figure 1D indicates that the emission intensity of Eu-FA is $591\left({ }^{5} \mathrm{D}_{0^{-}}{ }^{7} \mathrm{~F}_{1}\right) \mathrm{nm}$ and $617 \mathrm{~nm}\left({ }^{5} \mathrm{D}_{0^{-}}{ }^{7} \mathrm{~F}_{2}\right)$ upon excitation at $405 \mathrm{~nm}$. Doping of Eu ${ }^{3+}$ ions substitute part of the $\mathrm{Ca}^{2+}$ ions in the Eu-FA crystals. The proposed lattice models (Scheme 1) show several mechanisms by which $\mathrm{Eu}^{3+}$ ions incorporate into the apatite lattice, which is important for understanding the mechanism of synthesis of Eu-FA nanorods. The $\mathrm{F}^{-}$ions in the FA crystal occupy a smaller space and have a weaker steric hindrance compared to the - $\mathrm{OH}$ groups in the HA crystal. In other words, the $\mathrm{F}^{-}$ions have a stronger interaction with $\mathrm{Eu}^{3+}$ ions than -OH groups $[11,14]$.
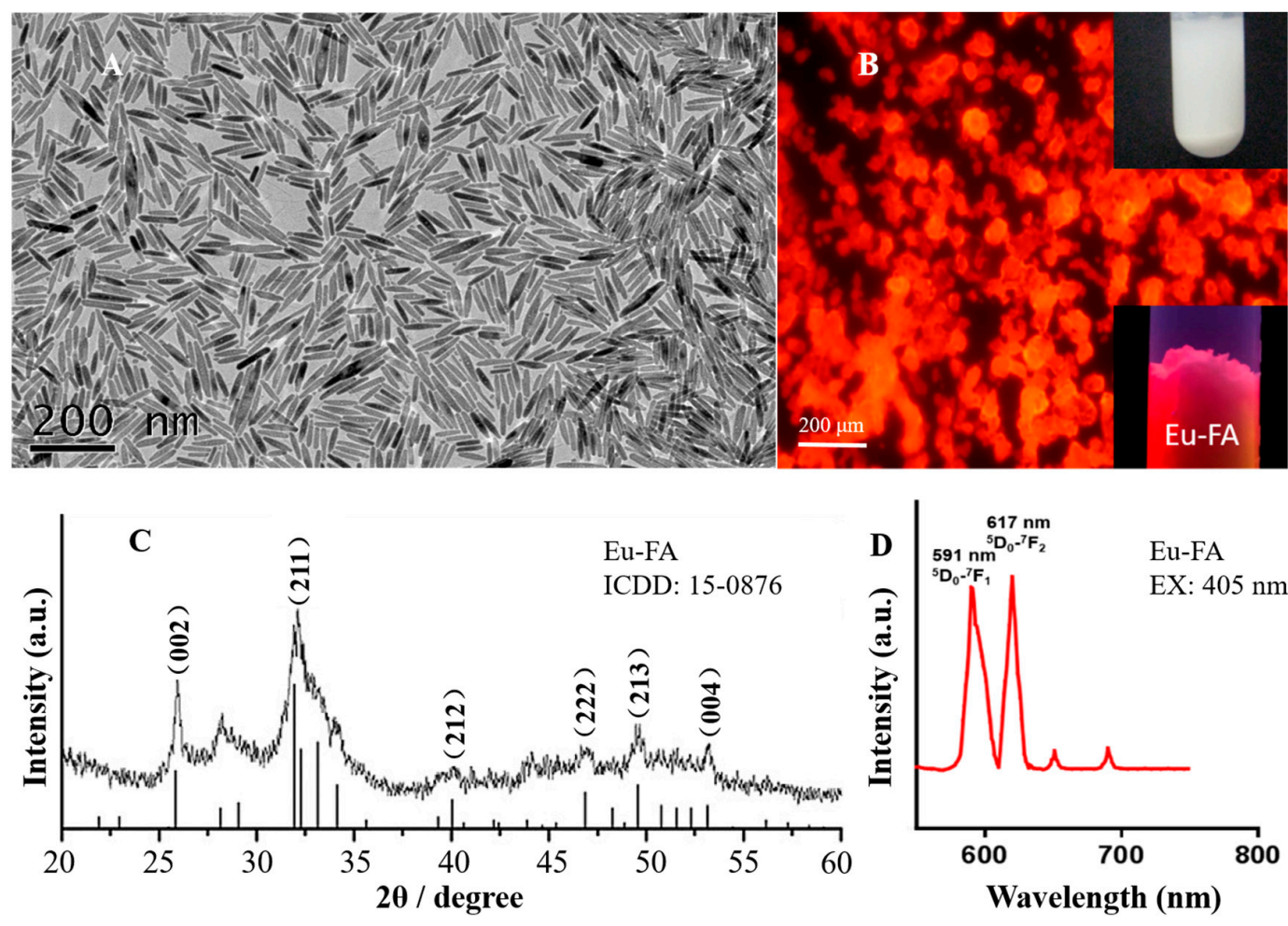

Figure 1. (A) TEM results for the europium-doped fluorapatite (Eu-FA) crystals indicate a rod-like morphology; (B) Eu-FA nanorod powder under UV light and fluorescence microscopy; (C) XRD patterns correspond to a classical hexagonal phase; (D) Emission intensity of Eu-FA excited at $405 \mathrm{~nm}$. 


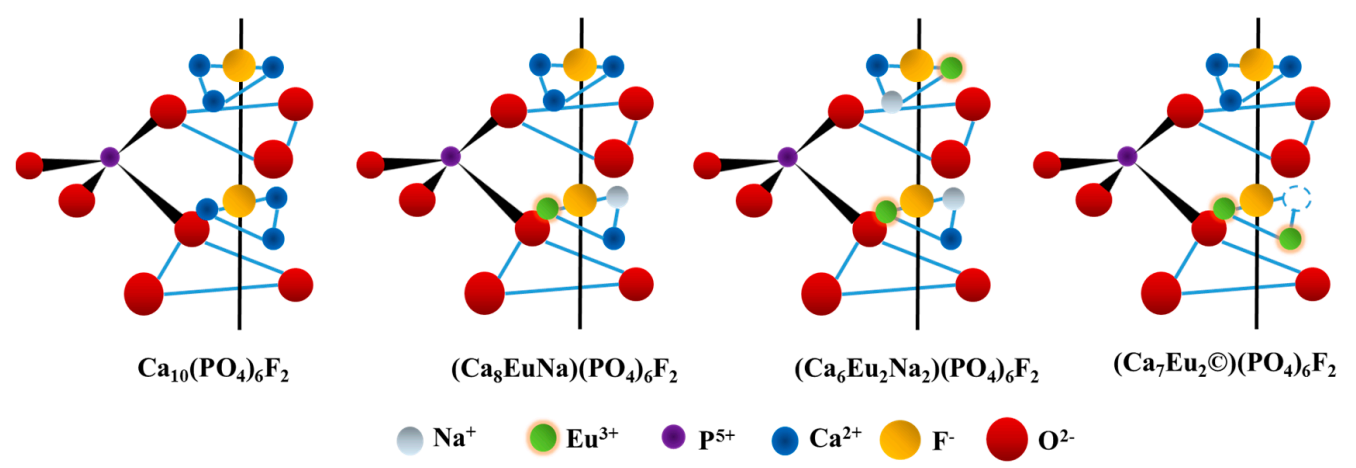

Scheme 1. Schematic diagram of different Eu-doping lattice models $\left(\mathrm{Ca}_{10}\left(\mathrm{PO}_{4}\right)_{6} \mathrm{~F}_{2},\left(\mathrm{Ca}_{8} \mathrm{EuNa}\right)\left(\mathrm{PO}_{4}\right)_{6} \mathrm{~F}_{2}\right.$, $\left(\mathrm{Ca}_{6} \mathrm{Eu}_{2} \mathrm{Na}_{2}\right)\left(\mathrm{PO}_{4}\right)_{6} \mathrm{~F}_{2},\left(\mathrm{Ca}_{7} \mathrm{Eu}_{2} \odot\right)\left(\mathrm{PO}_{4}\right)_{6} \mathrm{~F}_{2}$, $\odot$ means $\mathrm{Ca}^{2+}$ vacancy) along the fluorine channel of the FA crystal structure.

The DOX loading was recorded at a given nanocarrier content while varying the DOX concentrations from 0 to $5000 \mu \mathrm{g} / \mathrm{mL}$. The DOX loading amount increased gradually as the DOX concentration increased, and a maximum loading of $43.7 \%$ was achieved (Figure 2). The DOX molecules can be adsorbed onto the surface of the Eu-FA nanorods. DOX is a small molecule and can thus possibly be incorporated within the mesoporous or the hollow space. The high surface-to-volume ratio and the unique crystal structure make the Eu-FA nanorods easy to absorb DOX molecules. In addition, DOX has a pKa of 8.3 and is positively charged at a $\mathrm{pH}$ of 7.4. Therefore, DOX is attracted to the negatively charged nanocarriers without additional surface functionalization [15]. As DOX is oppositely charged to the Eu-FA surface and is small in size, its incorporation into the mesoporous should be easy, and even penetration into the hollow space of the nanorods should be possible [16].

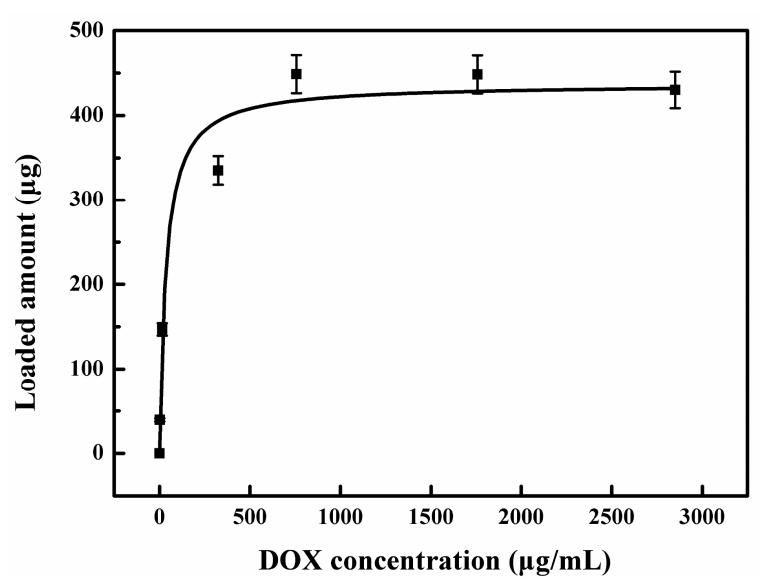

Figure 2. Doxorubicin (DOX) loading curve for Eu-FA, which was obtained by measuring the amount of DOX loaded onto the nanorods.

The loaded DOX was subsequently released into PBS with different $\mathrm{pH}$ values. Although a $\mathrm{pH}$ of 7.4 is representative of normal physiological conditions, an acidic $\mathrm{pH}$ of 5.5 is shared by the extracellular tissues of tumor cells [17]. The DOX molecules exhibited a significant $\mathrm{pH}$-dependent release (Figure 3). This $\mathrm{pH}$-sensitive phenomenon may be due to an increase in the hydrophilicity and solubility of DOX in acidic environments due to the stronger protonation of the $-\mathrm{NH}_{2}$ groups in the DOX molecules [18]. The DOX molecule contains various active and functional groups (such as $-\mathrm{C}=\mathrm{O},-\mathrm{COCH}_{2} \mathrm{OH},-\mathrm{OH}$, and $-\mathrm{NH}_{2}$ ), so it can easily inter-convert from one functional group to other by changing the $\mathrm{pH}$ value of the solution $[19,20]$. It is also easier to degrade the fluorapatite in an acid environment to promote DOX release. These reasons may contribute to why DOX has a faster release rate at $\mathrm{pH} 5.5$ than at 
pH 7.4. Low drug release efficacy is favorable for drug delivery, and the high DOX release rate in acidic environments is beneficial for killing tumor cells. The results of the drug release tumor cell apoptosis test confirmed this viewpoint.

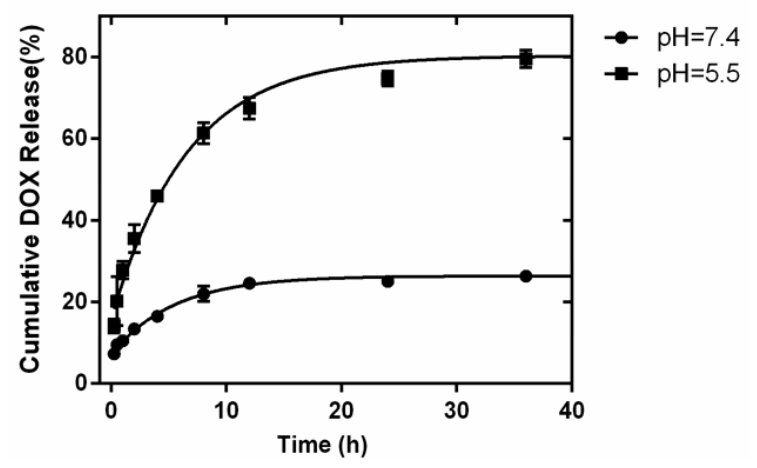

Figure 3. DOX release with different $\mathrm{pH}$ values $(\mathrm{pH}=5.5,7.4)$.

Next, the cellular uptake of Eu-FA was examined. The A375 cells were treated with $10 \mu \mathrm{g}$ of Eu-FA nanorods for $4 \mathrm{~h}$. The intracellular penetration of Eu-FA/DOX can be imaged in situ due to the self-fluorescence property. The location of the Eu-FA nanorods in the A375 cells was confirmed by confocal laser scanning microscopy. The red regions represent the fluorescence signal of Eu-FA, and the blue signals arise from the DAPI-stained nucleus. The red fluorescence signals of Eu-FA were observed in the cytoplasm (around the blue signals) or within the nucleus (coincident with the blue signals) of the A375 cells treated with DOX (Figure 4B). Therefore, only $4 \mathrm{~h}$ of treatment resulted in rapid uptake of the Eu-FA nanorods by the cells.
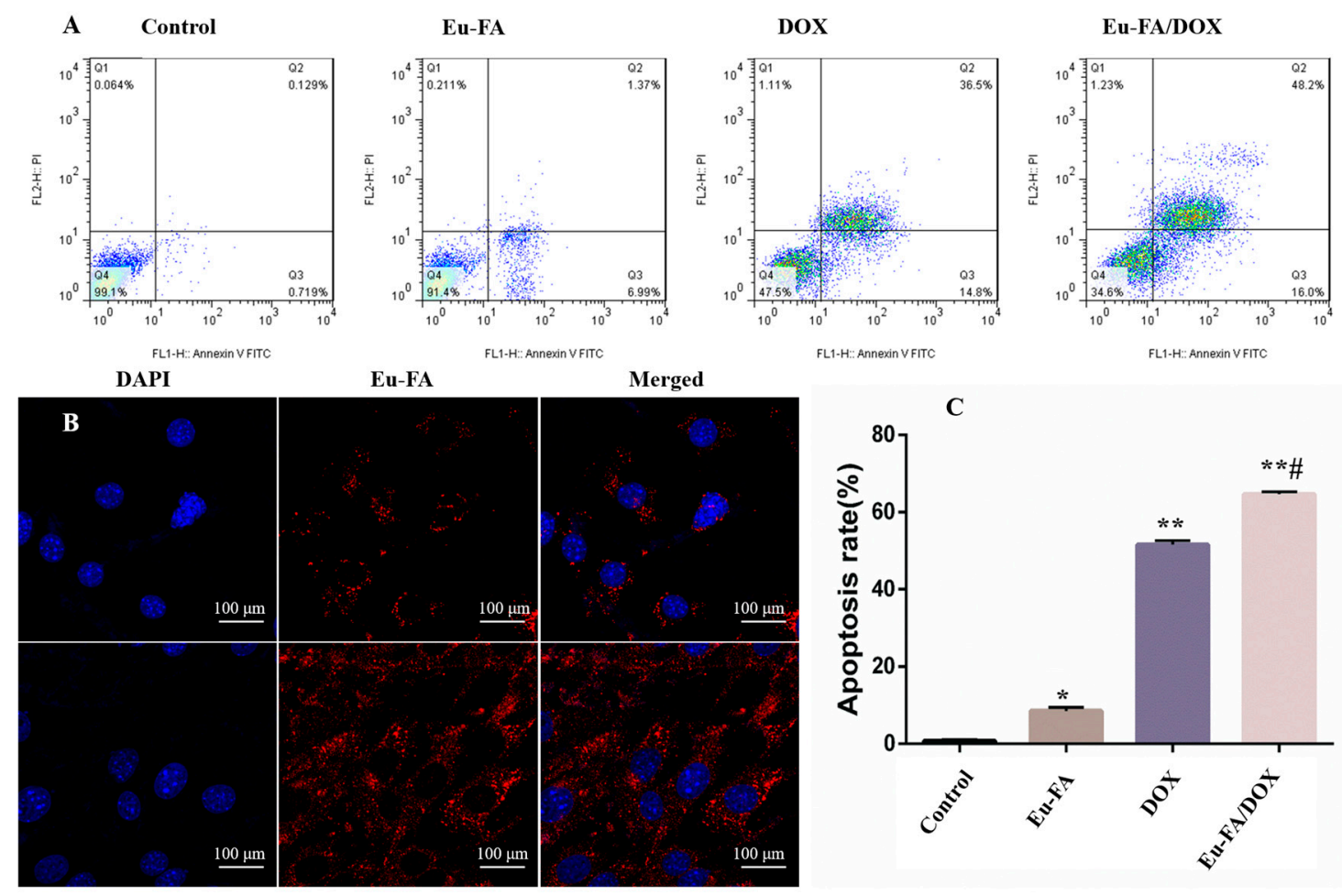

Figure 4. (A) Flow cytometry results for apoptosis after the A375 cells were treated with the control, Eu-FA $(40 \mu \mathrm{g} / \mathrm{mL})$, DOX $(17.48 \mu \mathrm{g} / \mathrm{mL})$ and Eu-FA/DOX (40 $\mu \mathrm{g} / \mathrm{mL}$ Eu-FA full loading with DOX); (B) Blue fluorescence from DAPI and red fluorescence from Eu-FA were observed in the cytoplasm or within the nucleus; (C) Statistical results of apoptosis in each group ( ${ }^{*} \#$ means $p<0.05$, ${ }^{* *}$ means $p<0.01$ ). 
To investigate the apoptosis rate induced by Eu-FA/DOX, the treated cells were double-stained with FITC-Annexin V and PI followed by analysis with flow cytometry. Propidium iodide (PI) was used in conjunction with Annexin $\mathrm{V}$ to determine if the cells were viable, apoptotic, or necrotic from differences in the plasma membrane integrity and permeability. This approach is a universal and accurate method for detecting cell apoptosis [21]. After a period of incubation, tumor cells will produce an acidic environment, and the $\mathrm{pH}$ value of the solution will undergo a dynamic change process and eventually attain a weak acidity. This acidic environment is conducive to the release of DOX in Eu-FA/DOX [22]. As shown in (Figure 4A,C), few apoptotic cells were detected in the untreated control. However, cell apoptosis was induced in the groups treated with DOX and Eu-FA/DOX (i.e., approximately $50.9 \%$ and $64.1 \%$, respectively). Interestingly, more apoptosis cells were observed with the Eu-FA/DOX treatment group compared to that with the DOX-only treatment group, and this difference was statistically significant. This means more apoptosis was observed when DOX was uploaded by the Eu-FA nanocarrier system. Therefore, in the group treated with Eu-FA, 8.31\% of the population exhibited apoptotic cells. The non-apoptotic cell fraction was considered to be necrotic (i.e., dying from a cause other than apoptosis). At this point, the cell death mechanism of the A375 cells treated with DOX is considered to be different from that of cells treated with Eu-FA/DOX.

\section{Materials and Methods}

\subsection{Synthesis of Eu-FHA Nanorods}

$\mathrm{Eu}^{3+}$-doped FHA nanoparticles were synthesized via a hydrothermal method (synthesized by the Institute of Biomedical Engineering, Peking University). All chemicals were analytical grade. Exactly $0.5 \mathrm{~g}$ of octadecylamine were dissolved in $4 \mathrm{~mL}$ of oleic acid while heating, and $16 \mathrm{~mL}$ of ethanol and an aqueous solution of $\mathrm{Ca}\left(\mathrm{NO}_{3}\right)_{2}(0.28 \mathrm{M}, 7.0 \mathrm{~mL})$ were then added while stirring. $\mathrm{NaF}(0.24 \mathrm{M}$, $2.0 \mathrm{~mL}), \mathrm{Eu}\left(\mathrm{NO}_{3}\right)_{3}(0.20 \mathrm{M}, 2.0 \mathrm{~mL})$, and $\mathrm{Na}_{3} \mathrm{PO}_{4}(0.20 \mathrm{M}, 7.0 \mathrm{~mL})$ were added to the solution followed by an additional $5 \mathrm{~min}$ of stirring. Then, the sealed flask was heated at $160{ }^{\circ} \mathrm{C}$ for $16 \mathrm{~h}$. The obtained mixture consisted of FA nanoparticles doped with $\mathrm{Eu}^{3+}$, and these nanoparticles were collected by centrifugation and freeze-dried.

\subsection{Characterization of Eu-FHA Nanorods}

Transmission electron microscopy (TEM) was carried out on a JEM-2100 instrument to determine the sizes and morphologies of the Eu-FHA nanorods. The samples were prepared by placing a drop of a dilute ethanol dispersion of the products on the surface of a copper grid. XRD analysis was performed using an Image Plate X-ray Diffractometer (RAPID-S, Rigaku, Japan) with Cu Ka radiation. The luminescence spectra were recorded on a Hitachi F-4500 fluorescence spectrophotometer. Luminescent photography of the sample was performed under UV light at $390 \mathrm{~nm}$.

\subsection{Preparation of the Drug Loading and Release System}

The DOX loading of Eu-FA nanorods were prepared using an absorption method. Doxorubicin hydrochloride (DOX, Shanghai Sangon, Shanghai, China) was dissolved in the PBS solution at $\mathrm{pH} 7.4$ to produce stock solutions with concentrations of $0,200,750,2000,3000,4000$, and $5000 \mu \mathrm{g} / \mathrm{mL}$. Five milligrams of the Eu-FA sample were ultrasonically dispersed in each DOX solution for 5 min, and then kept in a $37^{\circ} \mathrm{C}$ water bath for $12 \mathrm{~h}$. To quantify the drug-loading amount, the nanorods were centrifuged at 10,000 rpm for $5 \mathrm{~min}$, and the supernatant was gathered and detected by UV-vis spectrophotometer at an absorbance of $483 \mathrm{~nm}$.

To study the release curve of DOX from the nanocarrier samples, the as-prepared Eu-FA/DOX nanorods were used. A $2 \mathrm{mg}$ sample was dispersed in a $2 \mathrm{~mL}$ PBS solution (0.01 M, pH 7.4 and 5.5), followed by dialysis (3500 Dalton) in an air bath oscillator at $37^{\circ} \mathrm{C}$. The dialysis bag was placed in a buffer medium of $8 \mathrm{~mL}$, and the vibration was slow under the condition of $37^{\circ} \mathrm{C}$. At the different time points (15 min, $30 \mathrm{~min}, 2 \mathrm{~h}, 4 \mathrm{~h}, 8 \mathrm{~h}, 12 \mathrm{~h}, 1 \mathrm{~h}, 24 \mathrm{~h}, 36 \mathrm{~h}$ ), the amount of drug released into the medium 
was measured by using a UV-Vis spectrophotometer with an absorbance of $483 \mathrm{~nm}$, and the release rate was then calculated.

\subsection{Cell Culture and Fluorescence Imaging}

Melanoma A375 cells were seeded at $10^{5}$ cells in each well of 6-well culture plates and treated with Eu-FA nanorods at a concentration of $10 \mu \mathrm{g} / \mathrm{mL}$ for $4 \mathrm{~h}$. The fluorescent images were observed and analyzed using a laser scanning confocal microscope (LSM780, Carl Zeiss, Dresden, Germany). The cells were counterstained with DAPI (Invitrogen, Carlsbad, CA, USA) to observe the nucleus.

\subsection{Cell Apoptosis Detection}

The A375 cells treated with Eu-FA, DOX, or Eu-FA/DOX for $24 \mathrm{~h}$ were harvested. The concentration of the Eu-FA was $40 \mu \mathrm{g} / \mathrm{mL}$, the DOX concentration was $17.48 \mu \mathrm{g} / \mathrm{mL}$, which was calculated by the maximum drug loaded amount at the adsorption value of $43.7 \%$, and the initial $\mathrm{pH}$ value of the solution was 7.4. Flow cytometry was employed to detect cell death and apoptosis according to the manufacturer's instruction. After being harvested via trypsinization and lysed with ice-cold PBS, the cocultured cells with Annexin V-FITC (50 $\mathrm{g} / \mathrm{mL}$, Sigma, Saint Louis, MO, USA) were incubated for $15 \mathrm{~min}$ in a dark at room temperature. Then, the re-suspended cells were stained with propidium iodide (10 $\mu \mathrm{g} / \mathrm{mL}$, Sigma). A Becton Dickinson FACS/Calibur cytometer (BD Biosciences, Franklin Lakes, NJ, USA) was employed to analyze the Annexin V-FITC and propidium iodide signals.

\subsection{Statistics Analysis}

Statistical analysis was performed using the SPSS 22.0 software. Student's $t$-tests were performed to determine the statistical significance between experimental groups. $p<0.05$ was considered to indicate statistical significance. All results are expressed as the mean \pm standard.

\section{Conclusions}

In summary, the as-synthesized Eu-FA nanorods exhibited excellent photoluminescence and high drug-loading capacity. We believe that this multifunctional nanocarrier will generate further interest and open new avenues for research on the applicability of using these nanoparticles in cancer treatment.

Acknowledgments: The project was supported by the Zhejiang Provincial Natural Science Foundation for Young Scientists (Q16C100002).

Author Contributions: Haifeng Zeng and Haifeng Chen conceived and designed the experiments; Haifeng Zeng performed the experiments; Sufan Wu analyzed the data; Xiyu Li and Muyang Sun contributed materials; Haifeng Zeng wrote the paper.

Conflicts of Interest: The authors declare no conflict of interest.

\section{References}

1. Wu, Y.J.; Tseng, Y.H.; Chan, J.C.C. Morphology control of fluorapatite crystallites by citrate ions. Cryst. Growth Des. 2010, 10, 4240-4242. [CrossRef]

2. Jantová, S.; Theiszová, M.; Letasiová, S.; Birosová, L.; Palou, T.M. In vitro effects of fluor-hydroxyapatite, fluorapatite and hydroxyapatite on colony formation, DNA damage and mutagenicity. Mutat. Res. 2008, 652, 139-144.

3. Liu, H.; Chen, F.; Xi, P.; Chen, B.; Huang, L.; Cheng, J.; Shao, C.; Wang, J.; Bai, D.; Zeng, Z. Biocompatible fluorescent hydroxyapatite: Synthesis and live cell imaging applications. J. Phys. Chem. 2011, 115, 18538-18544. [CrossRef]

4. Chen, F.; Huang, P.; Zhu, Y.J.; Wu, J.; Zhang, C.L.; Cui, D.X. The photoluminescence, drug delivery and imaging properties of multifunctional $\mathrm{eu}^{3+} / \mathrm{gd}^{3+}$ dual-doped hydroxyapatite nanorods. Biomaterials 2011, 32, 9031-9039. [CrossRef] [PubMed]

5. Wang, F.; Liu, X. Multicolor tuning of lanthanide-doped nanoparticles by single wavelength excitation. Acc. Chem. Res. 2014, 47, 1378-1385. [CrossRef] [PubMed] 
6. Liu, Y.; Tu, D.; Zhu, H.; Chen, X. Cheminform abstract: Lanthanide-doped luminescent nanoprobes: Controlled synthesis, optical spectroscopy, and bioapplications. Chem. Soc. Rev. 2013, 42, 6924. [CrossRef] [PubMed]

7. $\quad$ Feng, R.; Jiang, F.L.; Wu, M.Y.; Chen, L.; Yan, C.F.; Hong, M.C. Structures and photoluminescent properties of the lanthanide coordination complexes with hydroxyquinoline carboxylate ligands. Cryst. Growth Des. 2010, 10, 2306-2313. [CrossRef]

8. Ou, Y.C.; Gao, X.; Zhou, Y.; Chen, Y.C.; Wang, L.F.; Wu, J.Z.; Tong, M.L. Magnetic properties and photoluminescence of lanthanide coordination polymers constructed with conformation-flexible cyclohexane-tetracarboxylate ligands. Cryst. Growth Des. 2015, 16, 946-952. [CrossRef]

9. Kariem, M.; Yawer, M.; Sharma, S.; Sheikh, H.N. Syntheses, crystal structure, luminescence, porosity and magnetic properties of three-dimensional lanthanide coordination polymers with 2-aminoterepthalic acid. ChemistrySelect 2016, 1, 4489-4501. [CrossRef]

10. Zeng, H.; Li, X.; Xie, F.; Teng, L.; Chen, H. Dextran-coated fluorapatite nanorods doped with lanthanides in labelling and directing osteogenic differentiation of bone marrow mesenchymal stem cells. J. Mater. Chem. 2014, 2, 3609-3617. [CrossRef]

11. Li, X.; Zeng, H.; Teng, L.; Chen, H. Comparative investigation on the crystal structure and cell behavior of rare-earth doped fluorescent apatite nanocrystals. Mater. Lett. 2014, 125, 78-81. [CrossRef]

12. Rulis, P.; Ouyang, L.; Ching, W.Y. Electronic structure and bonding in calcium apatite crystals: Hydroxyapatite, fluorapatite, chlorapatite, and bromapatite. Phys. Rev. B 2004, 70, 2806-2810. [CrossRef]

13. Saber-Samandari, S.; Nezafati, N.; Saber-Samandari, S. The effective role of hydroxyapatite based composites in anticancer drug delivery systems. Crit. Rev. Ther. Drug Carr. Syst. 2016, 33, 41. [CrossRef] [PubMed]

14. Di, W.; Wang, X.; Chen, B.; Lu, S.; Zhao, X. Effect of oh- on the luminescent efficiency and lifetime of tb3+-doped yttrium orthophosphate synthesized by solution precipitation. J. Phys. Chem. B 2005, 109, 13154. [CrossRef] [PubMed]

15. Sanson, C.; Schatz, C.; Meins, J.F.L.; Soum, A.; Thévenot, J.; Garanger, E.; Lecommandoux, S. A simple method to achieve high doxorubicin loading in biodegradable polymersomes. J. Control. Release 2010, 147, 428-435. [CrossRef] [PubMed]

16. Kwon, S.; Singh, R.K.; Kim, T.H.; Patel, K.D.; Kim, J.J.; Chrzanowski, W.; Kim, H.W. Luminescent mesoporous nanoreservoirs for the effective loading and intracellular delivery of therapeutic drugs. Acta Biomater. 2014, 10, 1431. [CrossRef] [PubMed]

17. Lee, E.S.; Gao, Z.; Bae, Y.H. Recent progress in tumor ph targeting nanotechnology. J. Control. Release 2011, 132, 164-170. [CrossRef] [PubMed]

18. Li, H.; Bian, S.; Huang, Y.; Liang, J.; Fan, Y.; Zhang, X. High drug loading ph-sensitive pullulan-dox conjugate nanoparticles for hepatic targeting. J. Biomed. Mater. Res. Part A 2014, 102, 150. [CrossRef] [PubMed]

19. Zhao, Z.; Meng, H.; Wang, N.; Donovan, M.J.; Fu, T.; You, M.; Chen, Z.; Zhang, X.; Tan, W. A controlled-release nanocarrier with extracellular $\mathrm{pH}$ value driven tumor targeting and translocation for drug delivery. Angew. Chem. Int. Ed. 2013, 52, 7487-7491. [CrossRef] [PubMed]

20. Kundu, B.; Ghosh, D.; Sinha, M.K.; Sen, P.S.; Balla, V.K.; Das, N.; Basu, D. Doxorubicin-intercalated nano-hydroxyapatite drug-delivery system for liver cancer: An animal model. Ceram. Int. 2013, 39, 9557-9566. [CrossRef]

21. Rieger, A.M.; Nelson, K.L.; Konowalchuk, J.D.; Barreda, D.R. Modified annexin v/propidium iodide apoptosis assay for accurate assessment of cell death. J. Vis. Exp. 2011, 50, 40. [CrossRef] [PubMed]

22. Estrella, V.; Chen, T.; Lloyd, M.; Wojtkowiak, J.; Cornnell, H.H.; Ibrahimhashim, A.; Bailey, K.; Balagurunathan, Y.; Rothberg, J.M.; Sloane, B.F. Acidity generated by the tumor microenvironment drives local invasion. Cancer Res. 2013, 73, 1524-1535. [CrossRef] [PubMed]

Sample Availability: Samples of the compounds are available from the authors.

(C) 2017 by the authors. Licensee MDPI, Basel, Switzerland. This article is an open access article distributed under the terms and conditions of the Creative Commons Attribution (CC BY) license (http:/ / creativecommons.org/licenses/by/4.0/). 